\title{
Can we predict birth asphyxia of neonates born from PPROM women?
}

\section{Adly Nanda Al Fattah*, Yuditiya Purwosunu, Ali Sungkar, Natasya Prameswari} Department of Obstetrics and Gynecology, Faculty of Medicine Universitas Indonesia, Cipto Mangunkusumo Hospital
Jakarta, Indonesia

Received: 17 July 2017

Accepted: 18 August 2017

\section{*Correspondence:}

Dr. Adly Nanda Al Fattah,

E-mail: adlynanda@yahoo.com

Copyright: (c) the author(s), publisher and licensee Medip Academy. This is an open-access article distributed under the terms of the Creative Commons Attribution Non-Commercial License, which permits unrestricted non-commercial use, distribution, and reproduction in any medium, provided the original work is properly cited.

\begin{abstract}
Background: To develop a simple and accurate method of predicting birth asphyxia of neonates born from preterm premature rupture of membranes (PPROM) women utilizing clinical parameters that are generally available before delivery in the practical setting.

Methods: A retrospective cohort was conducted at single tertiary hospital in Jakarta between January and December 2013. Subjects were PPROM women with singleton live pregnancy who had their delivery on 24 to 34 weeks of gestational age (GA). Primary outcome was birth asphyxia defined by 5 th minutes APGAR score $<7$. The variables studied were leukocyte counts, gestational age at PPROM, clinical chorioamnitis, severe preeclampsia, mode of delivery, and PPROM-admission duration. Prediction model was developed using logistic regression analysis.

Results: One hundred and seventy five out of 380 PPROM women registered in our database met the inclusion criteria. The incidence of BA was $14.29 \%$ (25/175). The cutoff value for maternal leukocyte counts and gestational age to predict birth asphyxia was respectively $12,450 / \mathrm{mm} 3$ (area under the curve $0.68,95 \%$ CI $0.57-0.80$ ) and 32 weeks (area under the curve $0.81,95 \%$ CI 0.70-0.92). A prediction model was developed consisted of GA at PPROM $<32$ weeks of GA $(\mathrm{OR}=9.58,95 \% \mathrm{CI} 3.32-27.62)$ and maternal leukocyte counts $>12,450 / \mathrm{mm} 3(\mathrm{OR}=3.6,95 \% \mathrm{CI}$ 1.11-11.63), (Final AUC=0.82 (95\%CI 0.74-0.89). Clinical chorioamnitis, severe preeclampsia, mode of delivery, PPROM-admission duration was not associated with birth asphyxia.

Conclusions: A prediction model to predict BA among PPROM women at 24-34 weeks GA was developed consisted of GA at PPROM and maternal leukocyte counts at patient's admission.
\end{abstract}

Keywords: Birth asphyxia, Neonates, PPROM

\section{INTRODUCTION}

In 2010 , there were $15.5 \%$ preterm births of all livebirths in Indonesia. ${ }^{1}$ Preterm premature rupture of membranes (PPROM) affected $3 \%$ of all pregnancies and is responsible for nearly one third of all preterm births. ${ }^{2}$ PPROM is one of the leading causes of perinatal morbidity and mortality, because it is associated with neonatal infection and umbilical cord compression due to oligohydramnios. $^{2-4}$ Birth asphyxia (BA) is one of the adverse outcomes occurred due to PPROM that can lead to severe hypoxic ischaemic organ damage in newborns followed by other life-long pathologies. ${ }^{5,6}$

BA remains a significant cause of infant death and neurodevelopmental impairment accounting for approximately $11-20 \%$ of all cases cerebral palsy. ${ }^{7}$ The definition of BA is still controversial. ${ }^{8}$ However in several studies, failure to initiate spontaneous respirations and/or 5-minute Apgar score $<7$ was used to define BA. ${ }^{9,10}$ Despite the vague definition, low Apgar score increases Neonatal Intensive Care Unit (NICU), positive 
pressure ventilation (PPV) requirements, respiratory distress syndrome (RDS), sepsis and intraventrucular hemorrhage (IVH) rates. ${ }^{11}$ It also associated with cerebral palsy and may affects later neurological impairments in children. ${ }^{7,12,13}$

Several attempts have been conducted to predict the adverse outcomes of nenonates born from PPROM women. Umbilical arterial lactate and neonatal resuscitation level, gestational age, cervical length, amniotic fluid and fetal serum interleukin-6 (IL-6), proteomic biomarkers, microbial invasion of the amniotic cavity, and acute histologic chorioamnitis have been studied to predict the neonatal morbidity of PPROM. ${ }^{14-16}$ Nevertheless, the selection of parameters and specific outcomes measured were particularly depend on the facilities and costs provided by each institution.

The aim of this study was to develop a simple, accurate method of predicting BA of neonates born from PPROM women, utilizing clinical parameters that are generally available before delivery.

\section{METHODS}

A retrospective cohort study was performed at Cipto Mangunkusumo Hospital, Jakarta between January and December 2013. Subjects were women with singleton live pregnancy suffered from PPROM who had their delivery on 24 to 34 weeks of GA. Informed consent was not applied due to the retrospective data used in this study retrieved from our delivery database. GA was established according to first-trimester ultrasound scan, or if not available, last menstrual period. Women with eclampsia, diabetes mellitus and/or congestive heart failure, known fetal congenital anomaly were excluded from this study. PPROM was diagnosed by a sterile speculum examination under aseptic technique revealing pooling of amniotic fluid in the vagina.

Primary outcome was birth asphyxia defined by $5^{\text {th }}$ minutes APGAR score $<7$ established by competent perinatology residents. Independent variables evaluated included clinical chorioamnionitis; severe preeclampsia; gestational age at delivery; PPROM to hospital admission-time; and leukocyte counts at pastient's admission to the delivery suite. Clinical chorioamnionitis was defined following the criteria of Gibbs et al as a temperature elevation $>37.8^{\circ} \mathrm{C}$ and $\geq 2$ of the following criteria: uterine tenderness, malodorous vaginal discharge, fetal tachycardia ( $>160$ beats/min), maternal tachycardia $(>100$ beats $/ \mathrm{min})$, and maternal leukocytosis $>15,000 / \mathrm{mm}^{3}$. $^{17}$

Two doses of intravenous Dexamethason $6 \mathrm{mg}$ given 24 hours apart, was administered from 24 to 34 weeks. Tocolysis was administered in all cases of clinical symptoms of preterm labor (PTL) in the absence of clinical chorioamnionitis, abruptio placentae, and fetal distress. The antibiotic regimen of choice in our institution was intravenous ampicillin $1.5 \mathrm{~g}$ every 6 hours.

Patients were diagnosed as preeclampsia if they met all of the following criteria: systolic blood pressure $\geq 140 \mathrm{~mm}$ $\mathrm{Hg}$ or diastolic blood pressure $\geq 90 \mathrm{~mm} \mathrm{Hg}$ on two occasions 6 hours apart, proteinuria $\geq 300 \mathrm{mg}$ per 24 hours or + using dipstick test. Severe pre-eclampsia was defined as systolic blood pressure $>160 \mathrm{~mm} \mathrm{Hg}$ or diastolic blood pressure $>110 \mathrm{~mm} \mathrm{Hg}$ measured at least twice 6 hours apart, proteinuria $>5000 \mathrm{mg}$ per 24 hours or $\geq++$ using dipstick test, eclampsia, platelet count persistently $<100,000 / \mathrm{mm} 3$, serum transaminases more than twice normal.

This study was approved by The Ethical Committee of Faculty of Medicine, Universitas Indonesia. There were four steps of analysis in this study, i.e. the descriptive and bivariate analysis using $\chi^{2}$ or Fisher test, ROC analysis to determine cutoff point of several risk factors, development of prediction model using logistic regression (included risk factors with $\mathrm{P}$ value $<0.25$ at bivariate analysis), and model simulation finding at the probabilities rate of the birth asphyxia using several possible cases scenario. All statistical analyses were conducted using software IBM $®$ SPSS $®$ Statistics version 20 (Armonk, NY: IBM Corp).

\section{RESULTS}

Table 1: Clinical characteristics of study population.

\begin{tabular}{|ll|}
\hline Variables & n \\
\hline Age & \\
\hline$<25, \mathrm{n}(\%)$ & $27(15.4 \%)$ \\
\hline $25-35 \mathrm{n}(\%)$ & $125(71.4 \%)$ \\
\hline$>35 \mathrm{n}(\%)$ & $22(12.6 \%)$ \\
\hline Parity & \\
\hline Primiparous n (\%) & $83(47.4 \%)$ \\
\hline $1 \mathrm{n}(\%)$ & $56(32.0 \%)$ \\
\hline $2 \mathrm{n}(\%)$ & $25(14.3 \%)$ \\
\hline $3 \mathrm{n}(\%)$ & $7(4.0 \%)$ \\
\hline$>3 \mathrm{n}(\%)$ & $4(2.3 \%)$ \\
\hline Birthweight, gram, (median, range) & $1885(500-$ \\
\hline $\begin{array}{l}\text { Gestational Age at birth, weeks, } \\
(\text { median, range) }\end{array}$ & $2800)$ \\
\hline Severe Preeclampsia & $32(24-34)$ \\
\hline Yes n $(\%)$ & \\
\hline No n (\%) & $6(4 \%)$ \\
\hline Clinical chorioamnitis & $169(96 \%)$ \\
\hline Yes n $(\%)$ & $19(10.8 \%)$ \\
\hline No n (\%) & $156(89.2 \%)$ \\
\hline Type of Cases & $8(4.6 \%)$ \\
\hline Booked Case n (\%) & $167(95.4 \%)$ \\
\hline Non-booked case n (\%) & \\
\hline
\end{tabular}

From January through December 2013, there were 380 PPROM women registered in our database. However, 
only 175 women met the inclusion criteria with PPROM between 24-34 weeks and complete information. Table 1 display subject characteritics based on demographic factors. Most of subjects were 25-35 years old women $(71.4 \%)$, primiparous $(47.4 \%)$ and referred by either primary or secondary health centers $(95.4 \%)$. GA at PPROM and birthweight were (median and range) 32 (24-34) weeks and 1885 (500-2800), respectively. The overall clinical chorioamnitis rate was $10.8 \%(19 / 175)$, and severe preeclampsia was found on $4 \%$ of the subjects. Birth asphyxia were found on $14.29 \%(25 / 175)$ of the subjects.
Receiving Operator Characteristics (ROC) curve analysis (Figure 1 and Figure 2) demonstrated that the best cutoff value for leukocyte counts and gestational age to predict birth asphyxia was respectively $12,450 / \mathrm{mm}^{3}$ (area under the curve 0.68 , 95\% CI $0.57-0.80$, Sensitivity $46.7 \%$, Specificity $88 \%$ ) and 32 weeks (area under the curve 0.81 , 95\% CI 0.70-0.92, Sensitivity 73\%, Specificity $80 \%$ ). PPROM-admission time cutoff was 10 hours (area under the curve 0.508 , 95\% CI $0.39-0.62$, sensitivity $68 \%$, specificity $42.3 \%$ ).

Table 2: Comparison of between asphyxia and non- asphyxia group based on obstetrical characteristics.

\begin{tabular}{|c|c|c|c|c|}
\hline Variables & Asphyxia (N=25) & Non-Asphyxia $(\mathrm{N}=150)$ & $\mathbf{P}$ & OR $(95 \% \mathrm{CI})$ \\
\hline \multicolumn{5}{|c|}{ Type of Delivery } \\
\hline $\mathrm{CS}$ & $12(48.0 \%)$ & $60(40 \%)$ & \multirow{2}{*}{$0.26^{*}$} & \multirow{2}{*}{$0.62(0.26-1.44)$} \\
\hline VD & $13(52.0 \%)$ & $90(60 \%)$ & & \\
\hline \multicolumn{5}{|c|}{ PPROM-admission time } \\
\hline$\geq 10$ hour & $17(68 \%)$ & $86(57.7 \%)$ & \multirow{2}{*}{$0.33 *$} & \multirow{2}{*}{$1.55(0.63-3.83)$} \\
\hline$<10$ hour & $8(32 \%)$ & $118(42.3 \%)$ & & \\
\hline \multicolumn{5}{|c|}{ Leukocyte Count } \\
\hline$\geq 12,450 / \mathrm{mm}^{3}$ & $21(84 \%)$ & $79(52.7 \%)$ & \multirow{2}{*}{$0.003 *$} & \multirow{2}{*}{$4.7(1.55-14.40)$} \\
\hline$<12,450 / \mathrm{mm}^{3}$ & $4(16 \%)$ & $71(47.3 \%)$ & & \\
\hline \multicolumn{5}{|l|}{ GA at PPROM } \\
\hline$\geq 32$ weeks & $5(20 \%)$ & $110(73.3 \%)$ & \multirow{2}{*}{$<0.0001^{*}$} & \multirow{2}{*}{$4.64(2.09-10.30)$} \\
\hline$<32$ weeks & $20(80 \%)$ & $40(26.7 \%)$ & & \\
\hline \multicolumn{5}{|c|}{ Clinical chorioamnitis } \\
\hline Yes & $2(8 \%)$ & $17(11.4 \%)$ & \multirow{2}{*}{$0.632 *$} & \multirow{2}{*}{$0.70(0.16-3.11)$} \\
\hline No & $23(92 \%)$ & $133(88.6 \%)$ & & \\
\hline \multicolumn{5}{|c|}{ Severe Preeclampsia } \\
\hline Yes & $0(0 \%)$ & $6(4 \%)$ & \multirow{2}{*}{$0.596 * *$} & \multirow{2}{*}{$0.96(0.91-0.97)$} \\
\hline No & $25(100 \%)$ & $144(96 \%)$ & & \\
\hline
\end{tabular}

* Chi Square, **Fisher's Exact test

After numeric variables was transformed into categoric data considering the cutoff values, the bivariate analysis was conducted (Table 2). GA at PPROM and leukocyte counts were significantly associated with birth asphyxia ( $\mathrm{p}<0.05$, Chi-Square). Eighty percent (20/25) asphyxia neonates were born at $<32$ weeks of gestational age. Twenty one out of 25 asphyxia neonates were born from PPROM mothers with leukocyte counts $>12,450 / \mathrm{mm}^{3}$ at presentation. Clinical chorioamnitis, severe preeclampsia, mode of delivery, PPROM-admission time were not associated with birth asphyxia. On multivariate analysis, logistic regression was performed included independent variables with $\mathrm{p}$ value $<0.25$ (leukocyte counts and GA at PPROM). The first step as well as final model was further transformed into a score system.

The logistic regrsesion resulted in formula below:

$\mathrm{Y}$ (birth asphyxia) $=-1.656+1.281$ (Leukocyte count) 2.259(Gestational Age at PPROM)
Notes:

leukocyte count $=1$, if $\geq 12,450 / \mathrm{mm} 3$, Leukocyte count $=0$ if $<12,450 / \mathrm{mm}^{3}$

Gestational Age $=1$ if $<32$ weeks, Gestatonal Age $=0$ if $\geq$ 32 weeeks.

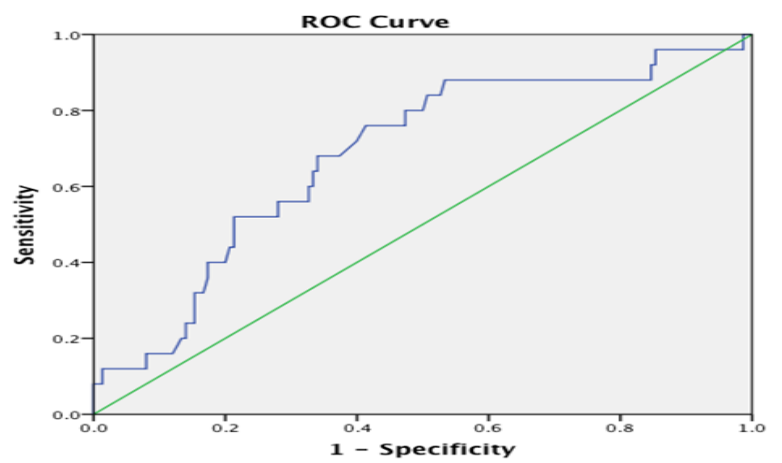

Figure 1: ROC of Leukocyte counts to predict birth asphyxia (AUC $=0.68 .4,95 \%$ CI 0.57-0.80). 
Table 3: Logistic regression analysis for birth asphyxia prediction model.

\begin{tabular}{|lllllllll|} 
& & B & S.E. & Wald & P & OR & 95\% C.I. \\
\hline \multirow{2}{*}{$\begin{array}{llllll}\text { Step } \\
1\end{array}$} & gestational age at PPROM $<32$ weeks & 2.259 & 0.55 & 17.477 & $0 .<0.0001$ & 9.58 & 3.32 & 27.62 \\
\cline { 2 - 9 } & Leukocyte $\geq 12,450 / / \mathrm{mm}^{3}$ & 1.281 & 0.60 & 4.59 & 0.032 & 3.60 & 1.11 & 11.63 \\
\cline { 2 - 8 } & Constant & -3.915 & 0.65 & 36.219 & $0 .<0.0001$ & 0.191 & & \\
\hline
\end{tabular}

Hosmer and Lemeshow test $\mathrm{p}=0.348$

Table 4: Probability of having birth asphyxia based on logistic regression formula on leukocyte and gestational age at birth model.

\begin{tabular}{|c|c|c|c|c|c|}
\hline Variable & Leukocyte cot & & Weeks of ge & l age & Probability \\
\hline & $\geq 12,450 / \mathrm{mm}^{3}$ & $<12,450 / \mathrm{mm}^{3}$ & $<32$ weeks & $\geq 32$ weeks & \\
\hline Case 1 & V & & $\mathrm{V}$ & & $40.73 \%$ \\
\hline Case 2 & & $\mathrm{~V}$ & $\mathrm{~V}$ & & $16.03 \%$ \\
\hline Case 3 & $\mathrm{~V}$ & & & $\mathrm{~V}$ & $6.69 \%$ \\
\hline Case 4 & & V & & $\mathrm{V}$ & $1.95 \%$ \\
\hline
\end{tabular}

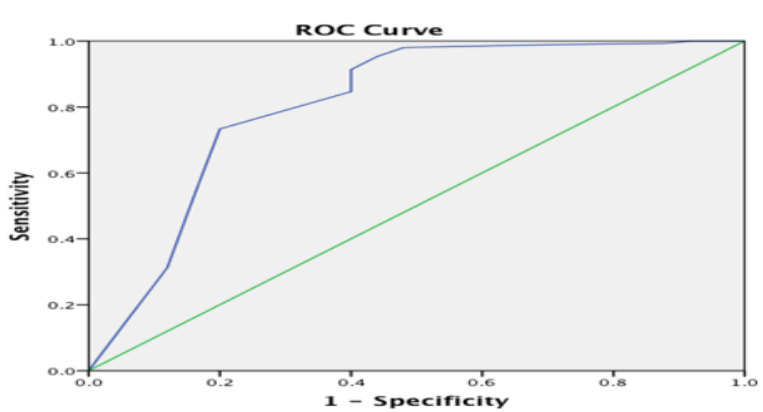

Figure 2: ROC of GA at PPROM to predict birth asphyxia $(\mathrm{AUC}=0.81,95 \% \mathrm{CI}$ 0.70-0.92).

Consequently 4 probabilities type of cases were developed as shown on the table 4. PPROM woman who has leukocyte count below $12,450 / \mathrm{mm}^{3}$ and admit to the hospital at more than 32 weeks of gestation will have only $1.95 \%$ chance to have asphyxia neonate. Conversely, they who have leukocyte count $\geq 12,450$ and $\geq 32$ weeks of GA at PPROM will have chance $40.73 \%$ to have their neonate's asphyxia. This model resulted in AUC of 0.82 (95\% CI 0.74-0.89) as shown in Figure 3.

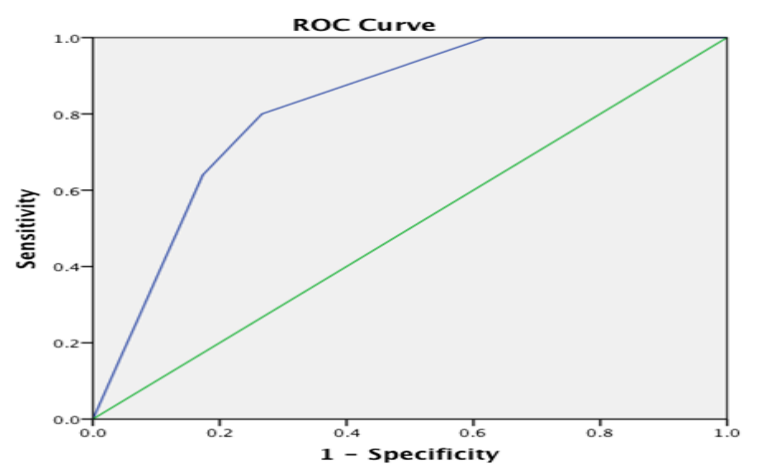

Figure 3: ROC of final model to predict birth asphyxia (AUC=0.82 (95\% CI 0.74-0.89).

\section{DISCUSSION}

The major finding in our study was an accurate and simple model to predict birth asphyxia using leukocytosis and GA at PPROM. To our knowledge this was the first study developing the model using widely available parameters i.e. maternal leukocyte counts and GA at PPROM to predict birth Asphyxia. Using the definition of 5th minutes Apgar score < 7, the incidence of BA in our study was $14.29 \%$. Kumari et al studied the trend of birth asphyxia were ranging from $5.8 \%$ to $7.2 \%$ during 1981 to 1988 in a single referral hospital. However, they used 1st minute Apgar score $\leq 6$ to define BA. ${ }^{18}$ Our study could be considered in practical settings, because though understanding of pathophysiology of asphyxia is progress significantly, predictive diagnostics studies are still limited. ${ }^{19}$

Weeks of GA at PPROM as a strong risk factor of adverse respiratory outcomes were obviously documented in several studies. ${ }^{20-22}$ Verspyck, et al concluded extreme prematurity (26-28 weeks) was an independent risk factor for perinatal adverse outcomes (odds ratio $(\mathrm{OR}) 43.9 ; \mathrm{p}=0.001) .^{5}$ In larger PPROM study, Neonatal outcomes improved as gestational age advanced. ${ }^{20}$ The correlation between leukocyte counts and birth asphyxia could possibly explained by fetal inflammatory response syndrome (FIRS) in PPROM. Maternal leukocyte count is one of the indicators of intrauterine infection as well as development of FIRS. Before labor, maternal leukocytes count of 11,810/mm3 could predict FIRS with the AUC of 0.61 (95\% CI $0.50-$ $0.71){ }^{23}$ FIRS defined by fetal plasma interleukin-6 (IL-6) concentrations $>11 \mathrm{pg} / \mathrm{mL}^{24}$ It significantly correlated with spontaneous preterm delivery among PPROM women. ${ }^{25}$ Moreover, it was associated with adverse neonatal outcomes including intraventricuar hemorrhage, early-onset sepsis, bronchopulmonary dysplasia, death, and RDS. ${ }^{26,27}$ In our study, $12,450 / \mathrm{mm} 3$ is the cutoff 
point to predict BA (AUC 0.68, 95\%CI 0.57-0.80, Sensitivity $46.7 \%$, Specificity $88 \%$ ). In addition, Gibbs, et al found $15,750 / \mathrm{mm}^{3}$ as significant mean level correlated with intraamniotic infection. ${ }^{18}$

Using multivariate analysis, maternal leukocyte counts and GA at PPROM were significantly associated with the birth asphyxia. In practice settings, the measurement of IL-6 is unavailable.

Therefore, as stated by Bartkeviciene, leukocyte count guides practitioners to predict FIRS. ${ }^{23}$ Hoffer compared the correlation between FIRS and adverse neonatal outcome between neonates less than 32 weeks' GA with neonates 32 weeks or longer, it shows nearly significant result $(\mathrm{P}=0.065) .{ }^{27}$ In our prediction model, the combination of leukocyte counts and GA at PPROM increased the AUC, from 0.68 and 0.81 respectively as sole predictors, to 0.82 for final model to predict BA (Figure 1-3).

However, in model simulation, the highest probability of BA was 40.73 percent. It possibly correlated with the complex pathophysiology of the BA. ${ }^{19}$ We believed that the occurrence of BA should be contributed by other factors that not measured in our study. However, by having the maternal leukocyte counts $<12,450 / \mathrm{mm} 3$ before delivery and GA at delivery more than 32 weeks, the probability of having BA neonates was predicted to be $1.95 \%$.

Our study offers several strengths: our high number of PPROM women allowed us to study the association between obstetrics parameters and neonatal outcome reliably. In additional, the comprehensive database allowed us to access pregnancy information that was obtained in a prospective manner.

However, our study has several weaknesses, mostly due to its retrospective design, such as the potential for missing data. We attempt to minimizing recall bias by directly reporting the data after delivery. It was done by well-trained obstetrics rand perinatology esidents on duty and rechecked by their consultants on duty. Other potential factros that possibly act as confiunding factors i.e. eclampsia, congenital anomaly, maternal systemic diseases had excluded from our study.

Also, deliveries occurred over a year period in a tertiary medical center, therefore study groups were identified from the same setting and time period, this is unlikely to have a significant effect to the outcome of the delivery.

\section{CONCLUSION}

A simple and accurate prediction model to predict birth asphyxia among PPROM women at 24-34 weeks GA was developed consisted of GA at PPROM and leukocyte counts at patient's admission. It could assist physician to give counselling regarding the prognosis of neonates.
Funding: No funding sources

Conflict of interest: None declared

Ethical approval: The study was approved by the Institutional Ethics Committee

\section{REFERENCES}

1. Blencowe H, Cousens S, Oestergaard MZ, Chou D, Moller A-B, Narwal R, et al. National, regional, and worldwide estimates of preterm birth rates in the year 2010 with time trends since 1990 for selected countries: a systematic analysis and implications. Lancet. 2012;379(9832):2162-72.

2. Mercer BM. Preterm Premature Rupture of the Membranes. Obstet Gynecol. 2003;101:78-93.

3. Newman DE, Paamoni-Keren O, Press F, Wiznitzer A, Mazor M, Sheiner E. Neonatal outcome in preterm deliveries between 23 and 27 weeks' gestation with and without preterm premature rupture of membranes. Arch Gynecol Obstet. 2008;280(1):711 .

4. Manuck TA, varner MW. Neonatal and early childhood outcomes following early vs later preterm premature rupture of membranes. Am J Obstet Gynecol. Mosby, Inc; 2014;211(3):308.e1-308.e6.

5. Verspyck E, Bisson V, Roman H, Marret S. Adverse respiratory outcome after premature rupture of membranes before viability. Acta Paediatr. 2013;103(3):256-61.

6. Golubnitschaja O, Yeghiazaryan K, Cebioglu M, Morelli M, Herrera-Marschitz M. Birth asphyxia as the major complication in newborns: moving towards improved individual outcomes by prediction, targeted prevention and tailored medical care. EPMA Journal. 2011;2(2):197-210.

7. Lie KK, Grøholt E-K, Eskild A. Association of cerebral palsy with Apgar score in low and normal birthweight infants: population based cohort study. BMJ. 2010;341:c4990.

8. Committee on Obstetrics Practice. Inappropriate use of the terms fetal distress and birth asphyxia. Int $\mathbf{J}$ Gynecol Obstet. 1998;61:309-10.

9. Ersdal HL, Mduma E, Svensen E, Perlman J. Birth asphyxia: a major cause of early neonatal mortality in a Tanzanian rural hospital. Pediatrics. 2012;129(5):e1238-43.

10. Jensen LV, Mathiasen R, Mølholm B, Greisen G. Low 5-min Apgar score in moderately preterm infants; association with subsequent death and cerebral palsy: a register based Danish national study. Acta Paediatr. Blackwell Publishing Ltd; 2012;101(2):e80-2.

11. Gezer A, Parafit-Yalciner E, Guralp O, Yedigoz V, Altinok T, Madazli R. Neonatal morbidity mortality outcomes in pre-term premature rupture of membranes. J Obstet Gynaecol. 2013;33(1):38-42.

12. Thibault M, Picaud J-C. Cognitive Impairment at Age 5 Years in Very Preterm Infants Born Following Premature Rupture of Membranes. J Pediatr. Elsevier Ltd; 2013;163(2):435-40.e2. 
13. Wolf MJ, Wolf B, Bijleveld C, Beunen G, Casaer P. Neurodevelopmental outcome in babies with a low Apgar score from Zimbabwe. Dev Med Child Neurol. 1997;39(12):821-6.

14. White CRH, Doherty DA, Henderson JJ, Kohan R, Newnham JP, Pennell CE. Accurate prediction of hypoxic-ischaemic encephalopathy at delivery: a cohort study. J Matern Fetal Neonatal Med. 2012;25(9):1653-9.

15. Clinical and inflammatory markers in amniotic fluid as predictors of adverse outcomes in preterm premature rupture of membranes. Am J Obstet Gynecol. Elsevier Inc; 2011;205(2):126.e1-e8.

16. Kacerovsky M, Musilova I, Andrys C, Hornychova H, Pliskova L, Kostal M, et al. Prelabor rupture of membranes between 34 and 37 weeks: the intraamniotic inflammatory response and neonatal outcomes. Am J Obstet Gynecol. Elsevier, 2014;210(4):325.e1-e10.

17. Gibbs RS, Blanco JD, St Clair PJ, Castaneda YS. Quantitative bacteriology of amniotic fluid from women with clinical intraamniotic infection at term. J Infect Dis. 1982;145(1):1-8.

18. Kumari S, Sharma M, Yadav M, Saraf A, Kabra M, Mehra R. Trends in Neonatal Outcome with Low Apgar Scores. Indian J Pediatr. 2007;60:415-22.

19. Morales P, Bustamante D, Espina-Marchant $P$, Neira-Peña T, Gutiérrez-Hernández MA, AllendeCastro C, et al. Pathophysiology of perinatal asphyxia: can we predict and improve individual outcomes? EPMA Journal. 2011;2(2):211-30.

20. Pasquier J-C, Picaud J-C, Rabilloud M, Claris O, Ecochard R, Moret S, et al. Neonatal outcomes after elective delivery management of preterm premature rupture of the membranes before 34 weeks' gestation (DOMINOS study). Eur J Obstet Gynecol Reprod Biol. 2009;143(1):18-23.

21. Pristauz G, Bauer M, Maurer-Fellbaum U, RotkyFast C, Bader AA, Haas J, et al. Neonatal outcome and two-year follow-up after expectant management of second trimester rupture of membranes. Int $\mathrm{J}$ Gynecol Obstet. 2008;101(3):264-8.

22. Saigal S, Doyle LW. An overview of mortality and sequelae of preterm birth from infancy to adulthood. The Lancet. 2008;371(9608):261-9.

23. Bartkeviciene D, Pilypiene I, Drasutiene G, Bausyte R, Mauricas M, Silkunas M, et al. Leukocytosis as a prognostic marker in the development of fetal inflammatory response syndrome. Libyan Journal of Medicine. 2013;8:8.

24. Gomez R, Romero R, Ghezzi F, Yoon BH, Mazor $\mathrm{M}$, Berry SM. The fetal inflammatory response syndrome. Am J Obstet Gynecol. 1998;179(1):194202.

25. Romero R, Gomez R, Ghezzi F, Yoon BH, Mazor $\mathrm{M}$, Edwin SS, et al. A fetal systemic inflammatory response is followed by the spontaneous onset of preterm parturition. Am J Obstet Gynecol. 1998;179(1):186-93.

26. Pilypienè I, Drazdienè N, Dumalakienè I, Vezbergienè N, Bartkevičienè D, Šilkūnas M, et al. The significance of fetal inflammatory response syndrome in early and later adaptation of premature infants. Archives of gynecology and obstetrics. 2015;291(1):67-72.

27. Hofer N, Kothari R, Morris N, Müller W, Resch B. The fetal inflammatory response syndrome is a risk factor for morbidity in preterm neonates. Am J Obstet Gynecol. 2013;209(6):542.e1-e11.

Cite this article as: Al Fattah AN, Purwosunu Y, Sungkar A, Prameswari N. Can we predict birth asphyxia of neonates born from PPROM women? Int J Reprod Contracept Obstet Gynecol 2017;6:423742. 